\title{
APPLICATION OF CRYSTALLISING HYDROPHOBIC MINERAL AND CURING AGENT TO FRESH CONCRETE
}

\author{
M M Rahman ${ }^{1}$, D.A Chamberlain ${ }^{2}$ \\ ${ }^{I}$ Department of Mechanical, Aerospace and Civil Engineering \\ Brunel University London \\ Kingston Ln Uxbridge, Middlesex UB8 3PH \\ ${ }^{2}$ Professor and Technical director \\ Epicuro Ltd, Moorfield House, Low Pastures, Swarland, Northumberland, UK
}

${ }^{\mathrm{T}}$ Corrosponding author, Phone: +44 (0)1895 267590,E-mail: mujib.rahman@brunel.ac.uk

\section{Research Highlight}

- A novel method has been proposed to optimise concrete hydration by crystallising hydrophobic treatment of concrete at the early stage of curing.

- Under 28 day adverse curing conditions, the combination of the crystallising hydrophobic and curing agent treatments provided the highest level of strength protection, preserving $74 \%$ of the design mix strength. This treatment combination also had the strongest effect in preventing increased permeability under adverse curing conditions.

- Under normal 28 day curing provisions, early application of a combination of crystallising hydrophobic mineral followed by a wax based curing agent, appears not to affect concrete strength and permeability. Furthermore, it appears that this combination of early treatments works to safeguard the strength and permeability of concrete against the negative effects of substandard curing provisions. 


\begin{abstract}
Whilst the use of curing agents is common practice in the production of reinforced concrete, it is not normal to apply protective treatments to freshly cast concrete. Such treatments, which are generally hydrophobic in nature, are commonly applied to matured concrete, as protection against chloride and water absorption and associated cyclic freeze thaw attack. One gateway issue in respect to the application of such surface treatments to fresh concrete, is its unavoidably high moisture content, which is known to substantially downgrade the effectiveness of silane and siloxane hydrophobic treatments. The possibility of protectively treating fresh concrete is interesting from the logistic and economic standpoints, in the matter of early completion of on-site works. Towards this advantageous position, it is interesting to observe that early surface treatment with a crystallising hydrophobic mineral solution, immediately followed by a curing agent application, safeguards the 28 day strength of concrete in an extremely adverse curing environment. Added to this, the treated concrete sorptivity values with protected curing and the adverse curing regime, are similar, indicating that concrete durability may also be protected by the combined surface treatment, applied as early as 3 hours following casting.
\end{abstract}

Key words: Fresh concrete, normally curing, adverse curing, curing agent, hydrophobic treatment, silane, toxicity, crystallising mineral, strength, sorptivity, durability.

1. Corresponding author

Submission date: 20/01/2016

Word count: 3000 , 8 Figures and 5 Tables 


\section{INTRODUCTION}

The UK has more than 61,000 highway and local road bridges, the vast majority of which are constructed in reinforced concrete, demanding an annual maintenance expenditure in excess of $£ 4 b n$ in 2012-2013, for example [1]. Structures in many UK regions suffer recurring adverse weather conditions, with instances of the highest recorded use of winter de-icing salts in Europe [2]. The UK also has one of the highest annual rainfalls in Europe, recorded at $1120 \mathrm{~cm}$ in 2014 [3]. To make matters worse, the correspondence between zones with overlapping wet and freezing conditions is strong, the West Highlands of Scotland being one example. Furthermore, predictions for towards the end of the 21st century, indicate that increasingly adverse weather will become more frequent and wider spread [4].

Whilst the need for effective concrete protection is of growing importance, there is, in parallel, increasing probability of high moisture content existing at the time of protective treatment application. Unfortunately, even modest increases in concrete moisture content above laboratory testing requirements, substantially downgrades the performance of silane and siloxane treatments against chloride penetration [5]. For this reason, the main driver in the ongoing research is 'alternative protective treatment materials', ones that are application moisture tolerate (AMT). In this reported investigation, Patented [6] crystallising hydrophobic mineral technology is employed that uses moisture in its curing process and, in this sense it is AMT, significantly contrasting with the dry conditions specified for other material treatments. A further characteristic of this crystallisation material, is its extremely low toxicity [7]. Constrastlingly, a substantially water diluted silane has been proved to be toxic in nature [8].

In this reported investigation, the crystallisation treatment has been applied to fresh concrete, this directly followed by the application of a non-permanent curing compound. The performance of this innovative combination is tested by comparing the 28 day strength and permeability outcomes for concrete subjected to normal or adverse curing conditions.

\section{BACKGROUND}

Two well established strategies for safeguarding the 'whole life' strength and durability of structural concrete are the application of a curing agent to fresh concrete, and a hydrophobic pore lining material to mature concrete. The main purpose of the former is to prevent loss of hydration water during concrete curing, thus avoiding associated effects such as surface shrinkage, cracking and reduced strength. Since 1986, in the UK [9], the latter has been applied with the intention of controlling moisture movement and ingress of chloride ions that cause active corrosion of steel reinforcement. In this reported study, early application of a combination of hydrophobic impregnation followed by a curing agent is investigated.

Under laboratory test conditions for 28 day concrete, hydrophobic impregnation materials of different chemistry have been found to comply with EN1504-2, the European Standard addressing concrete protection measures [10]. The prescriptive testing for this compliance, incorporates the test method defined in Appendix 2, UK Highway Agency's Design Manual for Road and Bridges [11]. Whilst this design manual points to high purity monomeric alkyl (isobutyl)-trialkoxy silane as a suitable hydrophobic material for concrete impregnation, it recognises the possibility of complaint alternatives. To date, such alternatives include siloxanes, aqueous silanes and siloxanes, silane emulsions and creams and crystallising solutions, all held complaint with EN1504-2. However, investigations show that achievable dosage, penetration and resistance to chloride ion penetration with silane and siloxane derived treatments, depend on the existence of low moisture content at their application time [12]. Of the complaint material types, only crystallisation materials are intended to work with the concrete moisture content.

A range of curing material and methods are applied in structural concrete production including membrane curing compounds, self-curing and accelerating concrete mix additives, concrete wrapping and waterproofing compounds [13]. In terms of chemistry, curing materials include silicate solutions, polyurethanes, acrylic polymer coatings, film forming polymetric compounds, durable resins, low viscosity acrylic solutions, emulsions, aqueous biodegradables and liquid waxes. Depending on the material type, these work on a permanent or temporary basis, the former intended to provide long term protection. To the best knowledge of the authors, there is no curing agent for which compliance with EN1504-2 is claimed. 


\section{OBJECTIVE}

The objective of this investigation is to determine the effect that a combination of a crystallising hydrophobic mineral and wax based curing agent, applied sequentially to fresh concrete, have on its 28 day strength and permeability, under normal and adverse curing conditions.

\section{INVESTIGATION METHOD}

\section{Concrete mix design}

For the purposes the investigation, C40 Concrete used, this designed in accordance with BS EN 206-1/BS 8500 [14]for a target strength of $40 \mathrm{MPa}$ ( $5801 \mathrm{psi}$ ) at 28 days, with water to cement ratio of 0.45 and slump value in the $30 \mathrm{~mm}-60 \mathrm{~mm}(1.18-2.36$ ins $)$ range. A number of trial mixes were investigated for this, with the adopted mix proportions given in table 1.

A control mix was prepared according to the constituent proportions given in table 1, for which compressive strength testing outcomes for 3 days, 7 days and 28 days are given in table 2 . The slump value was $49 \mathrm{~mm}$.

\section{Surface Treatments}

Both the crystallising hydrophobic and the following wax based curing agent, were brush applied, uniformly to all cube faces, according to the manufacturer's specified dosages. The crystallisation material uses moisture to from tightly adhering hydrophobic mineral crystals within the pores of the concrete, thus combating absorption of water and chlorides, which lead to corrosion of the embedded reinforcement. A wax based, bio-degradable curing agent was employed.

To determine the influence of the crystallisation and curing agent on strength and permeability, cases were run for concrete with separate and combined surface treatments, each with its own untreated controls. Table 3 gives the treatment schedule for both the normal and adverse curing regime cases. In the cases where the curing agent was applied, this was removed immediately prior to permeability testing.

\section{Treatment Age}

Wishing to apply the surface treatments as early as possible to the fresh concrete, it was decided to monitor the internal moisture content of the concrete, commencing from the time of mould filling. The intention of this is to determine approximately at what time the water demand for the hydration process commenced in the central region of the concrete ie the concrete mix passing from plastic to solid state. Whilst the surface would predictably reach this stage earlier, we did not wish to disturb the still solidifying interior, possibly weakening the concrete overall.

An electrical resistance method [15] was used to monitor the moisture environment within the curing concrete, with discreet moisture detection sensors located at the centre, half depth and surface of the cube (see figure 1). Figure 2 plots typical data sets for a $100 \mathrm{~mm}$ (4") cube, this indicating distinct separation between commencement of moisture reduction at the surface and internal locations, the former at approximately 28 minutes and the latter 27 minutes after casting. From the same graph, it is also apparent throughout the full depth, that the initially fast reduction in moisture content is substantially concluded at 120 minutes following casting. On the basis of these observations, it was decided to commence applying the crystallising hydrophobic at 180 minutes hours followed by the curing agent at 210 minutes. This arrangement allowed the hydrophobic solution to dry on the cube surface before applying the curing agent.

\section{Concrete curing}

Immediately following treatment of all cube surfaces with the crystallising hydrophobic and or curing compound, two 28 day curing regimes were initiated (i) half the cubes subjected to favorable curing and (ii) half to an adverse curing regime. The latter is illustrated in figure 3, where electric fans are used to continuously force air over the test concrete. Such an arrangement is intended to promote loss of essential hydration water, thus disadvantaging the concrete's strength and durability. Both curing regimes were initiated immediately following application of the surface treatments. 


\section{Strength determination}

Concrete strength was determined by cube crushing.

\section{Permeability testing}

To assess the probable effects on concrete durability, permeability was measured using the ISAT method (Initial Surface Absorption Test) in accordance with BS 1881-208 [16]. In the case of cubes treated with the curing agent, this material was first removed by abrading the cube surface with a dry abrasive paper. A digital microscope was used to confirm complete removal of the white curing material. Where occurring, the crystallising hydrophobic treatment was considered to be sufficiently penetrating not to be affected by the adopted method of removing the curing agent.

\section{RESULTS}

\section{Strength outcomes}

Outcomes for 7 and 28 day strength testing for normally cured concrete are given in table 4 . The last column is the difference between the treated case and its corresponding control, expressed as a percentage of that control value. Comparing each treatment case with its corresponding control indicates a small element of additional strength. Other than the case of combined crystallising hydrophobic and curing agent, treatment, giving $9 \%$ strength addition, this is probably not statistically significant. On this basis, none of the treatment provision had an adverse effect on concrete strength at 28 days.

Table 5 gives the 28 day average strength values for adversely cured, untreated control and treated concrete. Whereas the 28 day average strength of the normally cured controls (table 4 ) is in the region of $40 \mathrm{~N} / \mathrm{mm}^{2}$, table 5 gives strength values in the region of $17 \mathrm{~N} / \mathrm{mm}^{2}$. This serves to confirm that the adopted adverse curing regime is very destructive, incurring more than $50 \%$ concrete strength loss.

In spite of the harshness of the adverse curing environment, it is apparent that early application of the curing agent works to safeguard $47 \%$ strength loss relative to its control. Of particular interest, however, is the outcome for the combination of crystallising hydrophobic followed by the curing agent, this combination safeguarding $74 \%$ of strength relative to its untreated control.

It should be noted that application of the crystallising hydrophobic alone, at only 210 minutes concrete maturity, runs contrary to the manufacture's guidance for the product use. This case was run purely to understand the individual influences of this and the curing agent, and has no relevance to engineering practice. At the same time, it is apparent that this does work to safeguard $11 \%$ of 28 day strength, relative to its control.

Table 4 and 5 include observations on visible surface cracking, which occurred in all the control concrete subjected to adverse curing. Whilst this also occurred with the manufacturer's non-compliant application of their crystallising hydrophobic, subjected to the adverse curing environment, it is interesting to note that these cracks were filled with the crystallised mineral at 28 days. An example digital microscope image (x40) of this phenomena is shown in figure 5 . 


\section{Permeability outcomes}

Permeability was examined at 28 days, using the ISAT method, for adversely and normally cured concrete. The averaged outcomes are plotted in figures 6 and 7, respectively. Referring to figure 6, for adverse curing, concrete treated with the curing agent alone or the crystallising hydrophobic followed by the curing agent, are least affected. However, the controls and the other surface treatment cases, show higher levels of water absorption under the adverse curing regime.

Figure 7, for normally cured concrete, is plotted to the same vertical scale as figure 6 . This makes clear that the average 28 days ISAT values for normally cured concrete are significantly less than for adverse curing. The addition to figure 7 of the adversely cured control curve from figure 6 (red curve), reconfirms that the adopted adverse curing regime is extremely demanding, working to substantially increase the permeability of concrete to which it is applied. This would have implications for durability.

\section{CONCLUSIONS}

- The influence of early application of a crystallising hydrophobic mineral and or a wax based curing agent on 28 day strength, and permeability, has been determined, for normal and adverse curing regimes.

- The adopted 28 day adverse curing regime proved to be severe, leading to more than $50 \%$ strength loss in untreated concrete. Correspondingly, the permeability of untreated concrete was notably increased. It also caused surface cracking.

- In all cases, under normal 28 day curing, the application of surface treatments at 210 minutes age, generally produced small increases in strength relative to untreated concrete. Permeability values were correspondingly similar.

- With adverse curing, application of the curing agent, surface protectors or combinations of these at 210 minutes age, works to safeguard the 28 days strength and permeability of concrete relative to identically cured untreated concrete.

- Under 28 day adverse curing conditions, the combination of the crystallising hydrophobic and curing agent treatments provided the highest level of strength protection, preserving $74 \%$ of the design mix strength. This treatment combination also had the strongest effect in preventing increased permeability under adverse curing conditions.

- As a single treatment on fresh concrete, the crystallising hydrophobic mineral filled surface cracks in concrete subjected to the 28 day adverse curing regime. Similar cracks in the accompanying untreated concrete remained open.

- Under normal 28 day curing provisions, early application of a combination of crystallising hydrophobic mineral followed by a wax based curing agent, appears not to affect concrete strength and permeability. Furthermore, it appears that this combination of early treatments works to safeguard the strength and permeability of concrete against the negative effects of substandard curing provisions.

\section{ACKNOWLEDGEMENT}

The authors acknowledge the support of International Chem-Crete Corporation, Richardson, Texas, USA, in providing samples of their Patented materials. 


\section{REFERENCES}

[1] Comptroller and Auditor General, Maintaining strategic infrastructure: roads, Department for Transport and Highways Agency for parliament, HC 169 SESSION 2014-15 6 JUNE 2014

[2] European Task Force TG3 Snow and Ice Control on European Roads and Bridges, European Commission, August 2002.

[3] The World Bank, http://data.worldbank.org/indicator/2015 (accessed 21/07/2015).

[4] Climate: Observations, Predictions and Impacts, UK Met Office, Devon, 2011.

[5] Rahman M. M. et al, Moisture Efficacy of Impregnant in Concrete Protection, The Transportation Research Board (TRB) 95th Annual Meeting Washingto, D.C., Jan 2016

[6] Patent US7429295 B2 CCC100, Aqueous chemical mixture to mitigate water associated problems in concrete pavement's, International Chem Crete Corporation. Texas, USA.

[7] Test Report: Pavix CCC100, 48 Hour Acute Toxicity Test, Int. Chem-Crete Corp, Texas, 2006.

[8] Test Report, WB 40, 48 Hour Acute Toxicity Test. ASI, London, 2006.

[9] B.J.Brown, Silane Treatment of Concrete Bridges, PP 977-998, Protection of Concrete, Edit, R.K.Dhir and J.W.Green Pub E \& F.N.Spon, 1990.

[10]. BS EN 1504-2:2004 Products and systems for the protection and repair of concrete structures. Definitions, requirements, quality control and evaluation of conformity. Surface protection systems for concrete, European Commission, 2004.

[11] Design Manual for Roads and Bridges (DMRB), HD 43/03: The Impregnation of Reinforced and Pre-stressed Concrete Highway Structures Using Hydrophobic Pore-Lining Impregnant, Volume 2, Section 4, Highways Agency, 2013.

[12] Rahman, M.M., D.A Chamberlain D.A. et al, Performance of pore-lining impregnants in concrete protection by unidirectional salt-ponding test (U-SPT). Transportation Research Record, Journal of the Transportation Research Board, 2013.

[13] Kholia et al., Effect on Concrete by Different Curing Methods and Efficiency of Curing Compounds, International Journal of Advanced Engineering Technology, June, 2013

[14] BS 8500-1:2006 Concrete -Complementary British Standard to BS EN 206-1 -Part 1: Method of Specifying and. Guidance for the Specifier, Bristish Standards, 2006.

[15] Gonzalo Quincot, Miguel Azenha, Joaquim Barros, Rui Faria, Moisture Measurement, State of the art Methods to measure moisture in concrete, Guimarães, UM, 2011.

[16] BS 1881-208:1996, Testing concrete. Recommendations for the Determination of the Initial Surface Absorption of Concrete, British Standards, 1996. 
Table 1: Adopted concrete mix design

\begin{tabular}{|l|c|}
\hline \multicolumn{1}{|c|}{ Ingredient } & $\mathrm{kg} / \mathrm{m}^{3}\left(\mathrm{lb} / \mathrm{ft}^{3}\right)$ \\
\hline Cement $(42,5 \mathrm{~N})$ & $457(28.5)$ \\
\hline Water & $210(13.1)$ \\
\hline Fine aggregate & $660(41.2)$ \\
\hline Course aggregate & $1073(67.0)$ \\
\hline Total & $2400(149.8)$ \\
\hline
\end{tabular}

Table 2. Compressive strength values for adopted concrete $\mathrm{mix}\left(\mathrm{N} / \mathbf{m m}^{\mathbf{2}}\right)$

\begin{tabular}{|c|c|c|c|}
\hline Cube ID & $\begin{array}{c}3 \text { days strength } \\
\mathrm{MPa}(\mathrm{psi})\end{array}$ & $\begin{array}{c}7 \text { days strength } \mathrm{MPa} \\
(\mathrm{psi})\end{array}$ & $\begin{array}{c}28 \text { days strength } \\
\mathrm{MPa}(\mathrm{psi})\end{array}$ \\
\hline C1 & $30.1(4361)$ & & \\
\hline C2 & $27.4(3975)$ & & \\
\hline C3 & $30.34(4400)$ & & \\
\hline C4 & & $32.7(4743)$ & \\
\hline C5 & & $33.1(4801)$ & $43.7(6334)$ \\
\hline C6 & & $32.6(4728)$ & $42.3(6135)$ \\
\hline C7 & & & $42.6(6178)$ \\
\hline C8 & & & $42.9(6215)$ \\
\hline C9 & & $32.8(4757)$ & \\
\hline Average & $29.3(4249)$ & & \\
\hline
\end{tabular}

Table 3: Surface treatment and curing regime schedule

\begin{tabular}{|c|l|c|}
\hline \multicolumn{1}{|c|}{ Surface treatment } & Slump Value (cm) \\
\hline \multicolumn{1}{|c|}{ Normally Cured } & $4.5 \mathrm{~cm}$ \\
\hline NC1A-CC & $\begin{array}{l}|c| \\
7 \text { No. untreated controls } \\
7 \text { No. treated with curing agent }\end{array}$ & $5.5 \mathrm{~cm}$ \\
\hline NC2A-CP & 7 No. untreated controls & $5.0 \mathrm{~cm}$ \\
\hline NC3A-CPC & 7 No. treated with hydrophobic & \\
\hline & 7 No. treated with hydrophobic followed by curing agent & $5.0 \mathrm{~cm}$ \\
\hline FAC1B-CC & 7 No. untreated controls & $4.5 \mathrm{~cm}$ \\
\hline FAC2B-CP & 7 No. treated with curing agent & \\
\hline FAC3B-CPC & 7 No. untreated controls & \\
\hline & 7 No. untreated controls & $\mathrm{cm}$ \\
\hline
\end{tabular}

Table 4: Average strength outcomes for early surface treatments for normally cured concrete

\begin{tabular}{|c|c|c|c|c|}
\hline Case ID & $\begin{array}{l}7 \text { day average } \\
\text { Strength MPa }\end{array}$ & $\begin{array}{l}28 \text { days average } \\
\text { strength } \mathrm{MPa}\end{array}$ & Observation & $\begin{array}{l}\text { Preserved } \\
\text { strength }\end{array}$ \\
\hline \multicolumn{5}{|c|}{ NORMAL CURING } \\
\hline NAC1A-CC: untreated control & 21.0 & $41.2(5974)$ & No cracks & \multirow[b]{2}{*}{$4 \%$} \\
\hline $\begin{array}{l}\text { NAC1A-CC: treated with curing } \\
\text { agent }\end{array}$ & 23.5 & $42.8(6206)$ & No cracks & \\
\hline NAC2A-CP: untreated control & 22.7 & $39.9(5786)$ & No cracks & \multirow[b]{2}{*}{$5 \%$} \\
\hline $\begin{array}{l}\text { NAC2A-CP: treated with } \\
\text { hydrophobic }\end{array}$ & 24.1 & $42.0(6090)$ & No cracks & \\
\hline NAC3A-CPC: untreated control & 23.2 & $40.7(5902)$ & No cracks & \multirow[b]{2}{*}{$9 \%$} \\
\hline $\begin{array}{l}\text { NAC3A-CPC: treated with } \\
\text { hydrophobic followed by curing } \\
\text { agent }\end{array}$ & 22.1 & $44.2(6409)$ & No cracks & \\
\hline
\end{tabular}


Table 5. Strength outcomes for early surface treatment of adversely cured concrete

\begin{tabular}{|c|c|c|c|c|}
\hline Case ID & $\begin{array}{l}7 \text { day average } \\
\text { Strength } \mathrm{MPa}\end{array}$ & $\begin{array}{l}28 \text { days average } \\
\text { strength } \mathrm{MPa}\end{array}$ & Observation & $\begin{array}{c}\text { Added } \\
\text { strength }\end{array}$ \\
\hline \multicolumn{5}{|c|}{ ADVERSE CURING } \\
\hline NAC1A-CC: untreated control & 15.0 & $16.4(2378)$ & Fine cracks & \multirow[b]{2}{*}{$47 \%$} \\
\hline NAC1A-CC: treated with curing agent & 20.4 & $24.1(3494)$ & No cracks & \\
\hline NAC2A-CP: untreated control & 16.7 & $17.9(2596)$ & Fine cracks & \multirow[b]{2}{*}{$11 \%$} \\
\hline NAC2A-CP: treated with hydrophobic & 19.2 & $19.9(2886)$ & $\begin{array}{l}\text { Large cracks } \\
(>1 \mathrm{~mm}) \text { filled }\end{array}$ & \\
\hline NAC3A-CPC: untreated control & 15.4 & $17.1(2479)$ & Fine cracks & \multirow[b]{2}{*}{$74 \%$} \\
\hline $\begin{array}{l}\text { NAC3A-CPC: treated with hydrophobic } \\
\text { followed by curing agent }\end{array}$ & 22.1 & $29.7(4307)$ & No cracks & \\
\hline
\end{tabular}




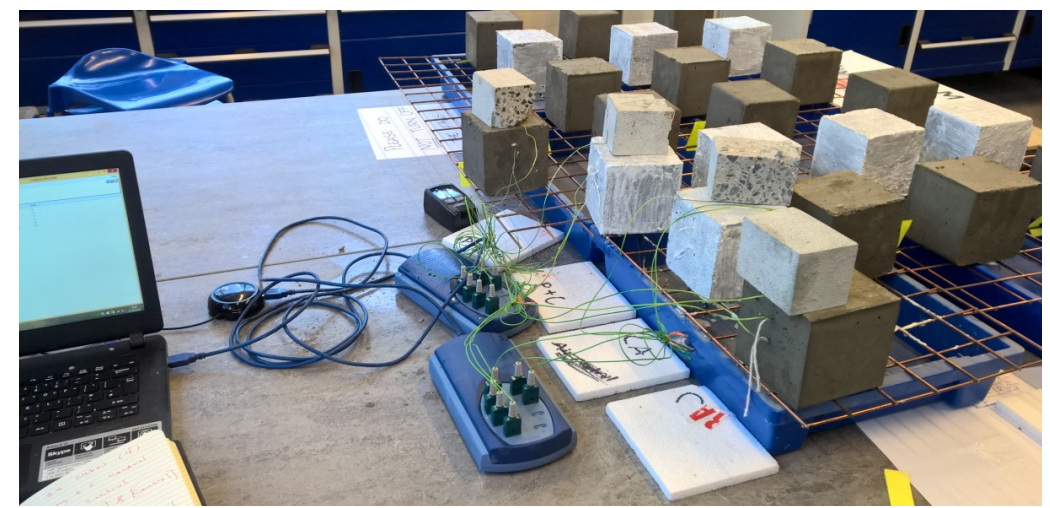

Figure 1: Embedded climatic monitoring of test cubes

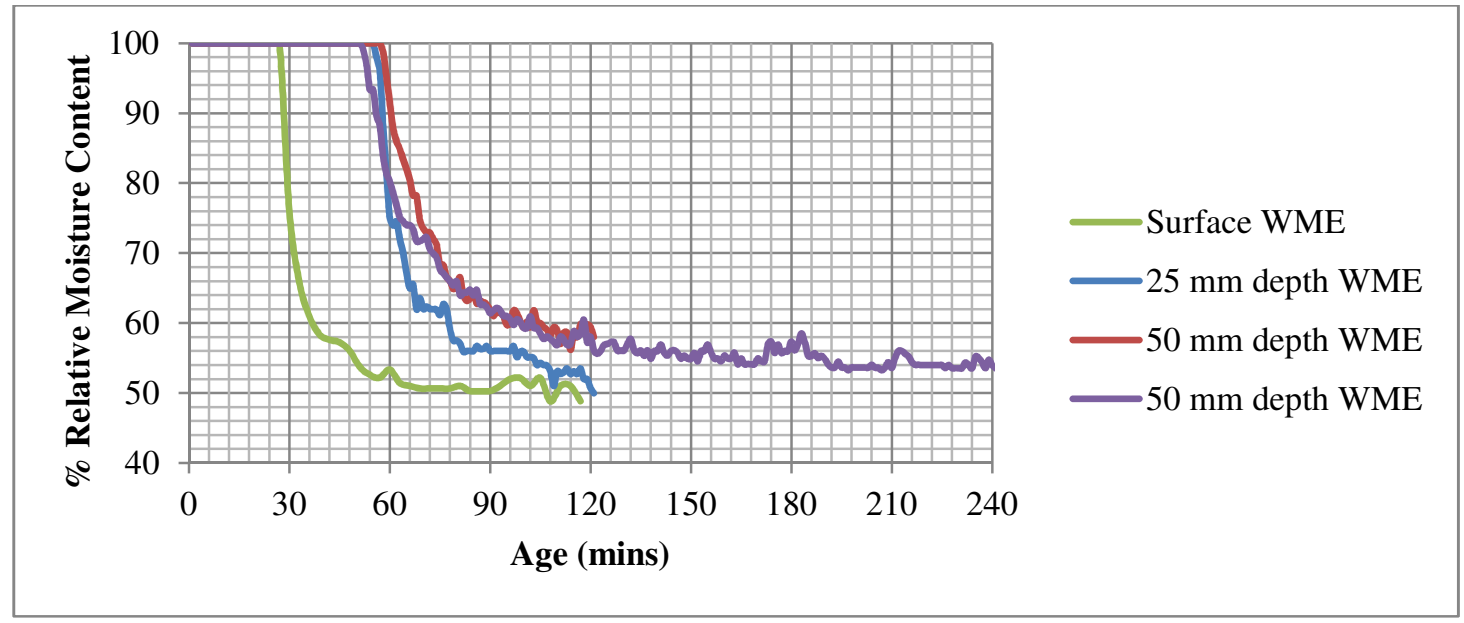

Figure 2: Reduction in WME moisture content through depth of concrete cube

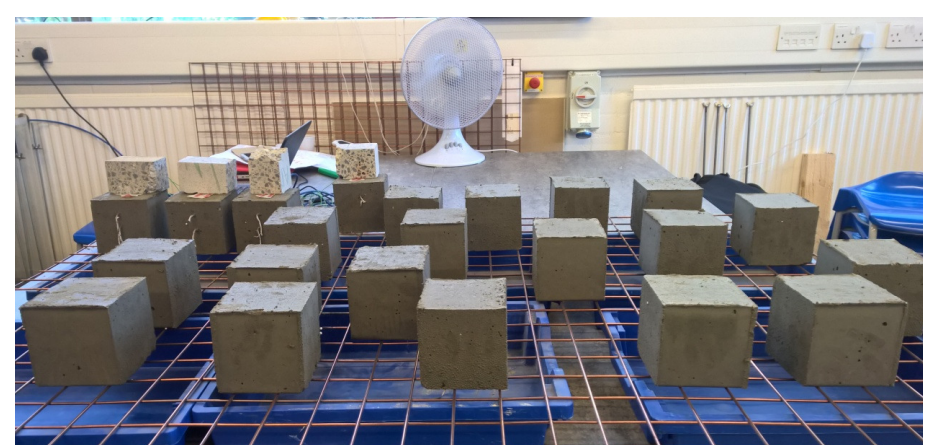

Figure 3: Adverse curing regime using forced air flow

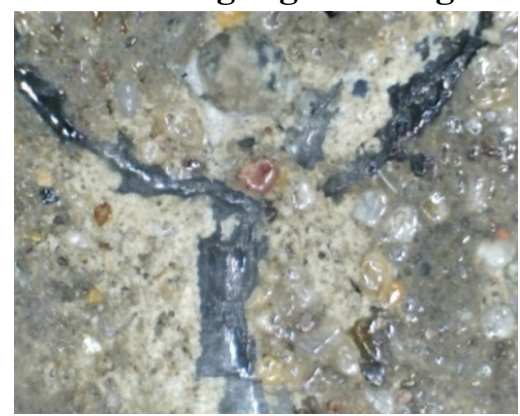

Figure 5. Large cracks (>1mm) filled with mineral crystals in adversely cured concrete. 


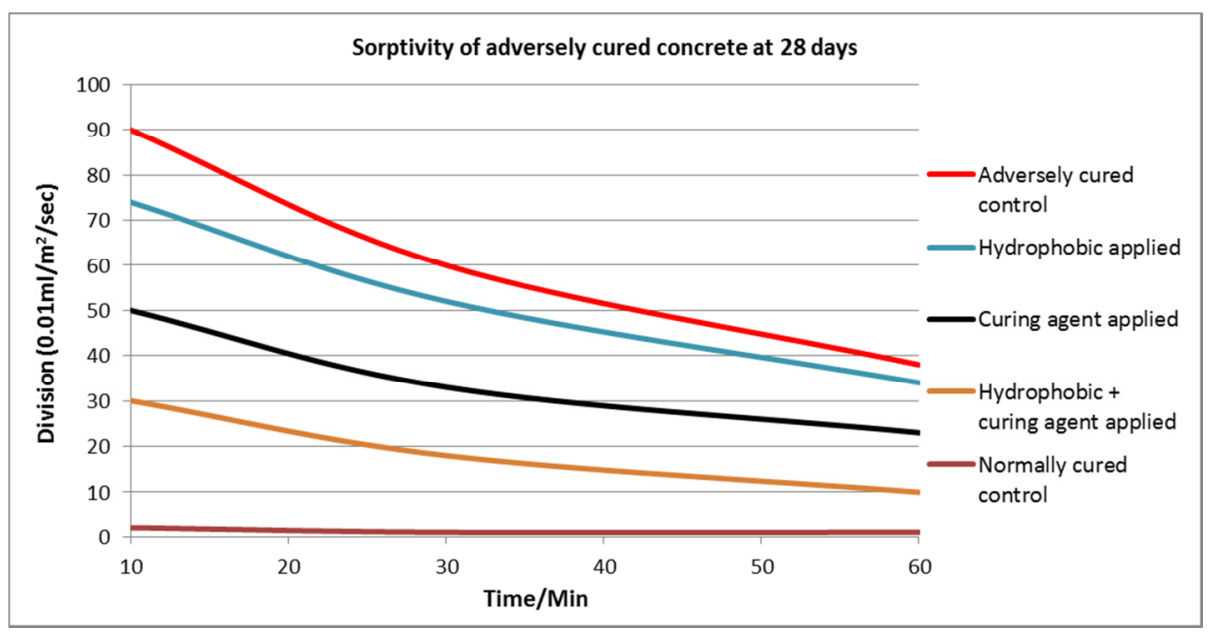

Figure 6. Average ISAT sorptivity values at 28 days for adversely cured concrete

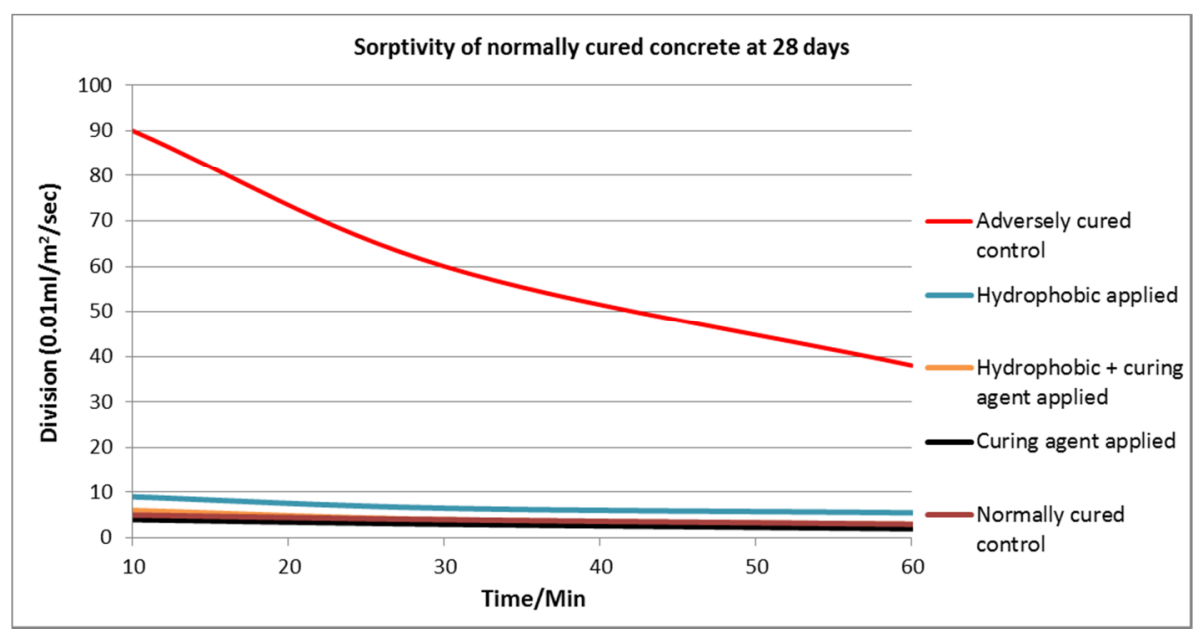

Figure 7. Average ISAT sorptivity values at 28 days for normally cured concrete 